INNOVATIONS IN PRIMARY CARE

\title{
Innovative Family Medicine and Behavioral Health Co-Precepting via Telemedicine
}

\author{
Alexander Kowalski, DO \\ Adarsh Gupta, DO \\ Tara Pellegrino, DO \\ Joanna Petrides, PsyD \\ Jennifer Sepede, DO \\ Meagan Vermeulen, MD, FAAFP \\ Department of Family Medicine, Rowan University School of \\ Osteopathic Medicine, Stratford, New Jersey
}

Ann Fam Med 2020;18:467. https://doi.org/10.1370/afm.2577.

\section{THE INNOVATION}

The onset of the COVID-19 pandemic created an opportunity to find a way to maintain a family medicine(FM)/behavioral health co-preceptorship model when treating patients and educating resident physicians via telehealth. The ability to identify and treat mental health disorders is a core skill for FM residents to acquire during training, therefore it was imperative to continue to find a way to provide this resource to residents and patients.

\section{WHO \& WHERE}

In our program at the Rowan University School of Osteopathic Medicine, FM residency core faculty members, physicians, and a clinical psychologist, work together with residents to see patients via telehealth from their respective remote locations. We maintain the traditional preceptorship model, which in our program includes regular co-precepting with our program clinical psychologist.

\section{HOW}

Our residents treat a wide range of mental health diagnoses in the office and regularly co-precept with a core faculty clinical psychologist; we felt it essential to continue having this asset available to our residents and patients via telehealth. Residents conduct telehealth visits from their homes, starting with an inde-

Conflicts of interest: authors report none.

\section{CORRESPONDING AUTHOR}

Alexander Kowalski, DO

Assistant Professor

Department of Family Medicine

Rowan University School of Osteopathic Medicine

Suite 2100, 42. E. Laurel Rd

Stratford, NJ 08084

kowalskia@rowan.edu pendent evaluation of the patient in a virtual visit. After the resident's initial assessment, residents reach out to their preceptors (also in their respective homes) via telephone to virtually precept with both a FM attending physician and a clinical psychologist. This is facilitated via access to the electronic health record and merged audio calls. Guidance is given on medication management (FM attending physician), behavioral interventions (clinical psychologist), and other psychosocial stressors (both) to educate the resident regarding treatment of general mental health disorders. At the conclusion of precepting, faculty then joins the resident in the virtual room to assist in the implementation of the agreed management plan and, if necessary, evaluate the patient further. After the virtual visit concludes, residents debrief with both preceptors on how the encounter progressed and their comfort in managing complex situations. Through this process, our residents have strengthened their observation, listening, and communication skills, which are crucial in the telemedicine environment and in treating behavioral health disorders. It also allows residents to learn about specific targeted interventions and alternative communication approaches with patients during this heightened period of stress. The final result has given residents tools to enhance patient care and increase resident comfort in managing mental health disorders in an unprecedented, challenging setting.

\section{LEARNING}

Our experience shows that resident co-precepting can be effectively done in a telehealth model. A properly defined, structured telemedicine residency preceptor model (as described above) can offer resident physicians valuable learning experience about the telehealth visit, as well as team-based interaction in a virtual environment. By maintaining the behavioral health component, the residents are better able to address the mental health needs of their continuity patients. As we move into a "new normal" that encompasses in-person visits and telehealth visits, we anticipate this model continuing as part of our residents' education. The improved skills they have refined through this precepting model will transcend telemedicine and apply to patient care in all settings. We recommend this innovation as a promising complementary tool for future physicians.

To read or post commentaries in response to this article, see it online at https://www.AnnFamMed.org/content/18/5/467.

Key words: telehealth; mental health; education/curriculum: residency training; COVID-19

Submitted May 12, 2020; submitted, revised, May 30, 2020; accepted June 8, 2020. 